\title{
FORMACIÓN ABIERTA. MEJORAR LA PRÁCTICA CLÍNICA CON LA MEJOR EVIDENCIA
}

\section{Open training. Improve clinical practice with the best evidence}

\author{
José Luis PARDAL-REFOYO \\ Director de Revista ORL. Ediciones Universidad de Salamanca. Salamanca. España. \\ Correspondencia: jlpardal@usal.es
}

Fecha de publicación: 21 de enero de 2018

Fecha de publicación del fascículo: 1 de marzo de 2018

Conflicto de intereses: Los autores declaran no tener conflictos de intereses Imágenes: Los autores declaran haber obtenido las imágenes con el permiso de los pacientes Política de derechos y autoarchivo: se permite el autoarchivo de la versión post-print (SHERPA/RoMEO) Licencia CC BY-NC-ND. Licencia Creative Commons Atribución-NoComercial-SinDerivar 4.0 Internacional Universidad de Salamanca. Su comercialización está sujeta al permiso del editor

Revista ORL comienza el año 2018 con el compromiso de facilitar el acceso abierto (Open Access, OA) a la información a los lectores y de proporcionar a los autores un medio de publicación de sus artículos libre de cargas y, junto con Ediciones Universidad de Salamanca, renueva esta responsabilidad con el apoyo a la «Declaración de Sant Joan d'Alacant en defensa del acceso abierto a las publicaciones científicas del Grupo de Editores de Revistas Españolas sobre Ciencias de la Salud (GERECS)», firmado en las «ll Jornadas Internacionales Revistas Ciencias de la Salud (JIRCS)» celebradas en Sant Joan D'Alacant el pasado mes de noviembre, que defiende un enfoque diferente en la evaluación de la actividad de los autores mediante indicadores que valoren el contenido de los artículos y no sobre indicadores basados en el factor de impacto de la revista [1].
La declaración se basa en cuatro puntos [1]:

1. Adherirse a los criterios emanados de la reunión de marzo de 2017 de la European Open Science Policy Platform.

2. Alentar a nuestras instituciones a que respalden la Expresión de Interés OA2020 (https://oa2020.org/) y, en consecuencia, firmen sus principios.

3. Instar a las agencias de investigación a nivel nacional a poner en marcha políticas científicas que requieran a sus investigadores que depositen sus publicaciones en repositorios institucionales.

4. Teniendo en cuenta el compromiso social de las revistas en OA con la accesibilidad del conocimiento, incluyendo a la ciudadanía, se solicita el reconocimiento como mérito académico/profesional la publicación en revistas de acceso abierto que estén indizadas en plataformas comprometidas con 
la excelencia, como SciELO, Redalyc o DOAJ.

Como refieren Peset y cols. [2] «la ciencia abierta, ciencia enriquecida se sostiene sobre tres pilares: tecnología, colaboración y apertura en tres polos que dominan la infraestructura sociotécnica: la dimensión política, la dimensión técnica y la capacitación profesional...» por lo que «...se necesitan conocimientos propios de la comunidad médica, las capacidades procedentes de la disciplina de la gestión de la información, el sector tecnológico y conocimiento jurídico».

Para que un dato se considere abierto debe cumplir los requisitos resumidos en los principios FAIR (findable, accesible, interoperable, reusable) [2,3].

Muy interesante la afirmación de Remedios Melero y Ernest Abadal citando a Boulton, que nos invita a reflexionar al revelar que «Si el final del siglo XX apostaba claramente por el acceso al resultado de la investigación en su versión final, o producto acabado (llámense artículos, informes, comunicaciones científicas, o cualquier otra forma física de comunicación), el siglo XXI se aventura como el inicio de una nueva era en la que los datos resultados de la investigación juegan un papel protagonista en los productos derivados de la investigación» [3].

Recomiendo la lectura de estos tres artículos publicados en Revista ORL que nos ayudarán a entender mejor en qué punto nos encontra$\operatorname{mos}[1,2,3]$.

Por tanto, para gestionar los datos y los informes de investigación necesitamos, aparte de los conocimientos propios de la Otorrinolaringología, otros procedentes de la Documentación, de la Biblioteconomía y de la Edición con un soporte tecnológico adecuado.

Parece que se hace necesario un cambio de cultura hacia el acceso abierto a la información y la investigación basado en la formación sobre estos aspectos aparentemente alejados de la actividad científica y profesional pero que repercuten directamente sobre la evaluación de los autores por lo que resultan imprescindibles para conocer el entorno y exigir otras fórmulas de evaluación.

Conscientes de estas necesidades, Revista $O R L$ publica, difunde a través de las redes sociales y fomenta mediante actividades formativas contenidos sobre documentación para que autores y revisores tengan una perspectiva amplia que permita crear la necesaria cultura de acceso abierto.

En esta línea, Revista ORL mantiene tres actividades formativas presenciales relacionadas con la documentación y la metodología: celebra anualmente la Jornada de Actualización Sobre el Proceso Editorial (JAsPE) - de la que este año celebraremos la sexta edición en septiembre-, los cursos sobre lectura crítica -este año tercera edición en marzo- y la difusión de contenidos de documentación en el congreso anual de la Sociedad Otorrinolaringológica de Castilla y León, Cantabria y La Rioja (SORL CLCR) en el que disponemos de un tiempo dedicado a contenidos editoriales -el congreso anual se celebra a finales de mayo o principios de junio-.

La participación de Revista ORL en el congreso «Ecosistemas del Conocimiento Abierto (ECA 2017)» que se celebró en Salamanca los días 25,26 y 27 de octubre de 2017, con la comunicación «Nuevas vías de publicación para revistas biomédicas. El proyecto de Revista ORL de Ediciones Universidad de Salamanca» ha supuesto un nuevo enfoque para comprender mejor el carácter multidisciplinar y único de la ciencia. Aquí presentamos las líneas estratégicas del análisis que sobre la situación de Revista ORL analizaron los miembros del Comité Editorial orientadas a mejoras editoriales, en formación y en acreditación. Aunque desarrollaremos este tema en próximos artículos, sí es momento para reflexionar sobre la importancia del desarrollo de la difusión en abierto de la información científica y es aquí donde de la mano de las tecnologías de la información y la comunicación se abren oportunidades y perspectivas nuevas.

Esta orientación hacia el conocimiento abierto justifica el título de este editorial que encabeza la página web de la SORL CLCR «Formación abierta. Mejorar la práctica clínica con la mejor evidencia» (www.sociedadorl.com) y que resume la visión de Revista ORL como agente difusor y facilitador de la comunicación.

Revista ORL además apoya las actividades formativas de contenidos propios de Otorrinolaringología y disciplinas relacionadas, participando y publicando sus contenidos como la II Reunión Otoneurológica que celebramos en Valladolid el 18 de marzo con muy buena participación, consolidando una de las actividades especializadas más interesantes. 
Revista $O R L$ continúa las tres líneas estratégicas decididas. En el área editorial las mejoras en los formatos de publicación (como objetivo puesto en el formato XML JATS), incrementar su presencia en repositorios y buscadores especializados, facilitar el formato impreso continuando con la impresión bajo demanda, mejorar su política de datos compartidos incrementando la publicación de documentación complementaria junto a los artículos y mejora en la identificación de autores utilizando el identificador ORCID. Mantener las actividades formativas propias y participar en actividades y grupos de trabajo sobre documentación que mejoren el conocimiento sobre acceso abierto (open access, open data, open science). Por último, continuar trabajando en la acreditación de Revista ORL por organismos nacionales e internacionales e incrementar su visibilidad en buscadores biomédicos.

Comenzamos un nuevo año editorial con ánimos renovados. Doy las gracias a los autores por confiarnos sus artículos, a los revisores por dedicar el tiempo que no tienen a mejorar los contenidos, al Comité Editorial por su apoyo, a Ediciones Universidad de Salamanca por todo el trabajo técnico imprescindible y el trato humano.

Como siempre deseo a todos nuestros lectores un provechoso 2018 y os invito a seguir colaborando con Revista ORL.

\section{BIBLIOGRAFÍA}

1. Sanz-Valero J. Declaración de Sant Joan d'Alacant en defensa del acceso abierto a las publicaciones científicas, del Grupo de Editores de Revistas Españolas sobre Ciencias de la Salud (GERECS). Revista ORL [Internet]. 7 Ene 2018 [citado 7 Ene 2018]; En prensa. $4 p$. Disponible en: http://revistas.usal.es/index.php/24447986/article/view/17318.

2. Peset F, Ferrer-Sapena A, GarzónFarinós F. Documentación en Otorrinolaringología. Compartir datos de investigación de Otorrinolaringología en un ecosistema de ciencia abierta. Revista ORL [Internet]. 6 Ago 2017 [citado 8 Ene 2018]; En prensa. 7p. Disponible en: http://revistas.usal.es/index.php/24447986/article/view/16800.

3. Melero-Melero R, Abadal-Falgueras E. Maredata, una iniciativa para el flujo de datos compartidos. Revista ORL [Internet]. 19 Sep 2017 [citado 21 Ene 2018]; En prensa. 7p. Disponible en: http://revistas.usal.es/index.php/24447986/article/view/16988.
ENLACES DE INTERÉS

- CORDIS - EU research projects under Horizon 2020 (2014-2020)

- DATASEA

- DMPtool

- Ecosistemas del Conocimiento Abierto (ECA 2017)

- EU Open Data Portal

- European Open Science Cloud

- European Open Science Policy Platform. Research \& Innovation. Open Science

- Force11

- HORIZON 2020. The EU Framework Programme for Research and Innovation
- Jornadas Internacionales

Revistas Ciencias de la Salud (JIRCS)

- OA2020

- Research Data Storage Facility

- Revista ORL. Enlace aTwitter. @RevistaORL

- Revista ORL. Impresión bajo demanda

- Revista ORL. Página de información sobre formación

- Revista ORL. Sociedad Otorrinolaringológica de Castilla y León, Cantabria y la Rioja.

- San Francisco Declaration on Research Assesment, DORA, 2012 
ACTIVIDADES FORMATIVAS DE REVISTA ORL SOBRE DOCUMENTACIÓN Y METODOLOGÍA EN 2017:

- Azofra-Agustín E, Pardal-Refoyo JL. La edición de revistas biomédicas de acceso abierto. En XXV Congreso de la Sociedad Otorrinolaringológica de Castilla y León, Cantabria y La Rioja, Salamanca 1, 2 y 3 de junio de 2017.

- Ochoa-Sangrador, C, Pardal-Refoyo JL, Navazo-Eguía A. Jornada de Actualización sobre el Proceso Editorial. 5ª Edición. ¿Cómo pensar y publicar un artículo de revisión? Evidencia y Recomendación: Cómo Seleccionar y Jerarquizar la Evidencia (GRADE). Hospital Universitario de Burgos, 23 de septiembre de 2017.

- Palomar LM. Lectura crítica de artículos. Análisis crítico de un artículo: Ensayo clínico. 31 de marzo de 2017. Facultad de Medicina y Odontología de la Universidad de Salamanca.

- Pardal-Refoyo JL; Azofra-Agustín E; Ferreras-Fernández T; Martín-Rodero H; RederoHernández A. Nuevas vías de publicación para revistas biomédicas. El proyecto de Revista ORL de Ediciones Universidad de Salamanca. PECHAKUCHA 3. Conocimiento abierto: experiencias de innovación y desarrollo. Presentado en Ecosistemas de Conocimiento Abierto 2017. Salamanca 25, 26 y 27 de octubre de 2017. https://eca.usal.es/es/programa. 